Revista Brasileira de

Engenharia Agrícola e Ambiental

v. 15, n.1, p.67-74, 2011

Campina Grande, PB, UAEA/UFCG - http://www.agriambi.com.br

agriambi

Protocolo 185.09 - 07/12/2009 • Aprovado em 22/10/2010

\title{
Distribuição espacial de valores prováveis de precipitação pluvial para períodos quinzenais, em Guiné-Bissau
}

\author{
Sadjo Danfá ${ }^{1}$, Antônio M. da Silva ${ }^{1}$, Carlos R. de M ello ${ }^{1}$, G ilberto Coelho ${ }^{1}$, \\ Marcelo R. Viola ${ }^{1} \&$ Léo F. Ávila ${ }^{1}$
}

\begin{abstract}
RESU MO
Neste trabalho se estimaram os valores prováveis de precipitação pluvial para períodos quinzenais e suas respectivas distribuições espaciais, em Guiné-Bissau. Utilizou-se a distribuição log-normal a dois parâmetros para estimar os valores prováveis de precipitação associados ao nível de probabilidade de $75 \%$, entre os meses de junho a outubro. A variabilidade espacial foi estimada pela modelagem dos semivariogramas experimentais e expressa com o emprego do interpolador espacial krigagem. Em média pode-se esperar, para períodos quinzenais em 3 de cada 4 anos pelo menos $100 \mathrm{~mm}$ de chuvas, excetuando-se a 1 a quinzena de junho e a $2^{\text {a }}$ quinzena de outubro, cujos valores estimados estão abaixo de $50 \mathrm{~mm}$. Essas duas quinzenas correspondem, respectivamente ao início e ao fim do período de chuvas sinalizando, portanto, a necessidade de uso de irrigação suplementar para os cultivos agrícolas, visto que, em junho ocorre a semeadura e outubro antecede a colheita para culturas de ciclo longo. Quanto à variabilidade espacial, ela é elevada, com evidente decréscimo dos índices pluviométricos do eixo sul-sudoeste, exceto no mês de setembro, quando há homogeneidade espacial nas duas quinzenas.
\end{abstract}

Palavra-chave: variabilidade espacial de precipitação, mapeamento de chuvas

\section{Spatial distribution of probable rainfall in Guinea-Bissau}

\begin{abstract}
The aim of this study was to estimate the probable values of rainfall in the first and second halves of the months and its spatial distribution in Guinea-Bissau. Distribution functions Log-normal 2 parameters were used to estimate the probable values of rainfall adopting the probability level of $75 \%$. The spatial interpolation (kriging) was applied by semi-variogram modeling demonstrating that the probable rainfall estimates have high spatial variability, except in the month of September, when the behavior is homogeneous for both first and second halves. The lowest probable values of rainfalls under $50 \mathrm{~mm}$ occur in June and $O$ ctober throughout the country, supporting the use of supplemental irrigation to avoid compromising the periods of sowing (June) and minimize damage at harvest (O ctober, N ovember) for long cycle crops.
\end{abstract}

Key words: spacial variability of precipitation, rainfall, mapping 


\section{INTRODUÇÃO}

A República de Guiné-Bissau é um país independente, localizada na África Ocidental, entre as coordenadas geográficas de 11 e $12^{\circ} \mathrm{N}$ (Latitude), e 14 a $16^{\circ} \mathrm{W}$ (Longitude); com uma geomorfologia simples e com poucas alterações de altitudes, o País se situa na transição entre zonas bioclimáticas de floresta, savana e estepe, com grande porção de suas terras inundada periodicamente. A maior parte do território está abaixo de $40 \mathrm{~m}$ e apenas a região leste apresenta cotas superiores a $300 \mathrm{~m}$ (Costa \& Resende, 1994).

Em Guiné-Bissau a agricultura representa mais de $61 \%$ do PIB e assegurou uma percentagem das receitas em divisas, que ascendeu a $77 \%$ em 2000. Os resultados do último recenseamento revelam que $83 \%$ da população ativa laboravam no setor primário (e majoritariamente na agricultura), 4\% no secundário (essencialmente na administração pública e serviços) e $13 \%$ no terciário (Manafá et al., 2005). São informações estatísticas que confirmam a importância da agricultura e do conjunto do setor primário, no crescimento econômico, na criação de empregos e na redução da pobreza interna.

A distribuição e o comportamento das precipitações pluviais são fatores básicos para o planejamento das atividades agrícolas, tais como: definição de datas de preparo de solo e semeadura, dimensionamento de vertedouros, redes pluviais, estruturas de proteção contra erosão e enchentes e elaboração de projetos de irrigação suplementar. Tendo-se em conta esses aspectos, pode-se dizer que o volume de chuva que cai em uma região é fator determinante da atividade agrícola a ser ali desenvolvida.

Os estudos probabilísticos da distribuição pluviométrica desempenham papel relevante no planejamento racional da produção agrícola, pois, conhecendo-se, com certa margem de segurança, a lâmina mínima a precipitar em certa região agrícola, pode-se realizar um planejamento eficiente de irrigações suplementares além de permitir o aumento das áreas cultivadas pelo uso otimizado da água disponível.

O estudo de valores prováveis de chuva pode ser feito por meio de algumas distribuições estatísticas, dentre as quais se destacam, segundo Back (2001), a distribuição log-normal a dois parâmetros, distribuição log-normal a três parâmetros, distribuição Pearson tipo III, distribuição Log-Pearson tipo III e distribuição de extremo tipo I, também conhecida como distribuição de Gumbel.

Apesar da reduzida extensão territorial, $36.125 \mathrm{~km}^{2}$ e uma morfologia simples com poucas alterações de cotas, a GuinéBissau apresenta uma variação de precipitação que engloba cerca de $2380 \mathrm{~mm}$ na região sul do país até $1200 \mathrm{~mm}$ no extremo norte, fronteira com o Senegal (Sambu \& Cavalcanti, 2003). Estimativas preliminares para Bolama, Gabu e Bedanda (GuinéBissau), no que se refere às precipitações dos meses de maio e junho, mostram que em cada quatro anos em três chove mais de 170, 145 e 210 mm respectivamente (Costa \& Resende, 1994), e chuvas suficientes (quantidade e distribuição no tempo), capazes de atender à demanda hídrica das culturas (evapotranspiração) e às temperaturas dentro de limites que não afetam negativamente os processos fisiológicos das plantas cultivadas, são fatores determinantes para a produção vegetal (Doorenbos \& Kassam, 1994).

Para fins agrícolas os nívéis de probabilidade mais recomendados estão entre 75 a $80 \%$, significando que se pode esperar em média, em três de cada quatro anos (75\%) ou em quatro de cada cinco anos $(80 \%)$, respectivamente, a ocorrência, no mínimo, do valor estimado para determinado período do ano (Bernardo et al., 2006).

Diversos estudos visando ao mapeamento da precipitação têm sido desenvolvidos com aplicação de várias técnicas, uma vez que a disponibilidade de dados climáticos e hidrológicos é pequena se comparada com grandes extensões territoriais, em especial em países em desenvolvimento (Marquínez et al., 2003; Mello \& Silva, 2008).

O semivariograma é a ferramenta básica na estimação por meio da geoestatística, haja vista que expressa a estrutura de variação espacial, seu alcance e o grau de dependência espacial e permite a estimativa dos valores da variável estudada, para locais/áreas onde não existam informações, por intermédio da técnica de interpolação conhecida como krigagem, permitindo a construção de mapas de isolinhas ou tridimensionais para exame e interpretação da variabilidade espacial (Ribeiro Jr., 1995; Carvalho et al., 2002; Vieira, 2003; Mello et al., 2003; Buytaert et al., 2006).

O conhecimento da variabilidade da precipitação dá suporte a diversas atividades econômicas e limita os impactos dos distúrbios no ambiente físico e dimensões humanas correlatas (Cano \& Brandão, 2002).

Assim sendo, objetivou-se com este trabalho estimar os valores prováveis de precipitações em períodos quinzenais e analisar sua variabilidade espacial em Guiné -Bissau.

\section{Material e MÉTODOS}

Guiné-Bissau fica localizada a oeste da África (Figura 1), entre as coordenadas geográficas, 11 e $12^{\circ} \mathrm{N}$ (Latitude), de 14 a $16^{\circ} \mathrm{W}$ (Longitude) altitude máxima de $300 \mathrm{~m}$, com valores médios para as temperaturas máximas e mínimas, respectivamente, de 32,9 e $25,5^{\circ} \mathrm{C}$. De acordo com a classificação de Koppen, possui clima tropical úmido, tipo Aw (Worldwide Distribuition of Climatic Region, abril de 2006).
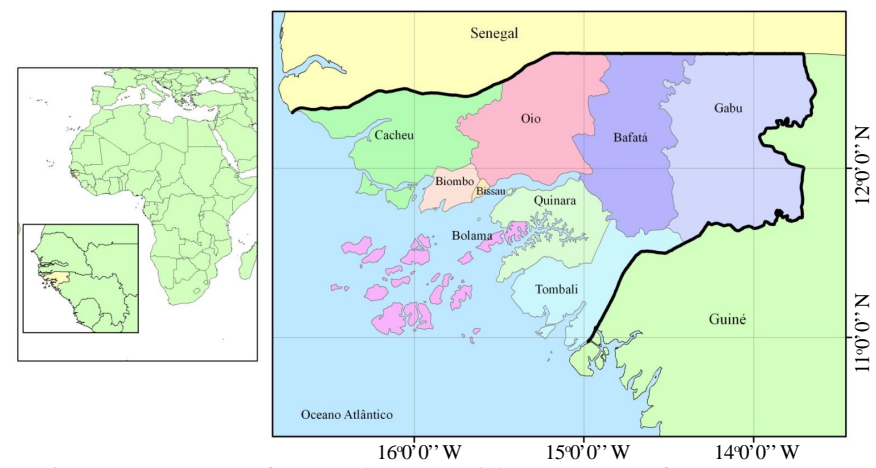

Figura 1. M apa do continente africano com destaque para a República de Guiné-Bissau, à esquerda, e suas divisões administrativas, à direita 
O período de chuvas em Guiné-Bissau é concentrado nos meses de junho a outubro de cada ano, representando $95 \%$ da precipitação anual.

Utilizou-se séries históricas de precipitação diária de 22 estações pluviométricas, com no mínimo 30 anos de monitoramento, compreendo o período à partir de 1950, as quais tiveram os meses de junho a outubro totalizados em duas quinzenas, constituindo-se desta forma as séries históricas de totais quinzenais.

Para estimativa do valor provável da precipitação com certo nível de probabilidade, utilizou-se a distribuição de probabilidade log-normal a dois parâmetros (média e desvio padrão), cuja função densidade de probabilidade (FDP) é dada por:

$$
\mathrm{FDP}=\frac{1}{\sigma_{\mathrm{n}} \cdot \sqrt{2 \cdot \pi}} \cdot \mathrm{e}^{-0,5\left(\frac{\left(\operatorname{Lnx}-\mu_{\mathrm{n}}\right)}{\sigma_{\mathrm{n}}}\right)^{2}}
$$

Esta distribuição é semelhante à distribuição Normal porém se trabalha com o logaritmo dos dados sendo, portanto, utilizada também a mesma função cumulativa de probabilidade (FCP), cuja equação geral proposta por Chow (1951), assume a seguinte forma:

$$
X_{\text {Prov }}=\mathrm{e}^{\mu_{n+2} \cdot \sigma_{n}}
$$

em que $X_{\text {Prov }}$ representa o valor provável de precipitação $(\mathrm{mm})$ com determinado nível de probabilidade, $\mu_{\mathrm{n}}$ e $\sigma_{\mathrm{n}}$, média aritmética e desvio padrão dos dados logaritmizados, z é a variável reduzida ou padrão da distribuição Normal ou de Gauss.

A aderência entre a distribuição de probabilidade e os dados utilizados foi verificada com base no teste de KolmogorovSmirnov. Este teste tem sido muitas vezes empregado para verificação do ajuste de distribuição de probabilidades em séries históricas de precipitação provável (Catalunha et al., 2002; Baú et al., 2006; Oliveira et al., 2010; Soccol et al., 2010).

Previamente à aplicação das ferramentas da geoestatistica, realizou-se a análise exploratória dos dados com o objetivo de analisar seu comportamento geral, identificar a presença de valores discrepantes conhecidos como outliers e de tendência dos dados, considerando-se a localização geográfica de cada observação.

Para o estudo da continuidade espacial da precipitação em Guiné Bissau, empregou-se o programa $\mathrm{R}$, com o pacote geoestatistica geoR (R Development Core Team, 2006). O modelo de semivariograma exponencial foi ajustado, uma vez que ele vem sendo aplicado com este objetivo, em diversos países, alcançando bons resultados (Martinez et al., 2003; Mello \& Silva, 2008; Mello et al., 2008; Avila et al., 2009; Viola et al., 2010), e se utilizou o alcance prático em substituição ao alcance teórico (Journel \& Huijbregts, 1978). Na fase de geração dos mapas dos valores prováveis de precipitação, trabalhou-se com uma extensão do ArcMap, do software ArcGIS 9.2 (ESRI, 2004).

Para se avaliar, de forma complementar, a qualidade da estrutura de dependência espacial, trabalhou-se com grau de dependência espacial, conforme Mello et al. (2005):

$$
\mathrm{GD}=\left(\frac{\mathrm{C}_{0}+\mathrm{C}_{1}}{\mathrm{C}_{0}}\right) \times 100
$$

em que GD é o grau de dependência (\%), $\mathrm{C}_{0}+\mathrm{C}_{1}$ é o patamar e $\mathrm{C}_{0}$, o efeito pepita, ambos extraídos do ajuste do semivariograma. Mello et al. (2005) apresentam a seguinte classificação para o GD: $\leq 25 \%$ (fraca estrutura de dependência espacial) entre 25 e $75 \%$ (moderado) e $>75 \%$ (forte).

\section{RESULTADOS E DisCUSSÃO}

Em termos de aderência da distribuição log-normal a 2 parâmetros aos dados, a aplicação do teste de KolmogorovSmirnov, com nível de significância de 5\% para as 220 séries trabalhadas, mostrou-se inadequada em apenas 12 delas, sendo a grande maioria associada ás precipitações da segunda quinzena de outubro. Diversos autores observaram boas características de ajuste da distribuição log-normal dois parâmetros as séries históricas de precipitação provável, recomendando e sugerindo seu uso (Longo et al., 2006; Junqueira Júnior et al., 2007; Ribeiro et al., 2007 Avila et al., 2009).

Verificaram-se dados discrepantes “outliers" (Figura 2), os quais produzem alta variabilidade podendo gerar distorção dos
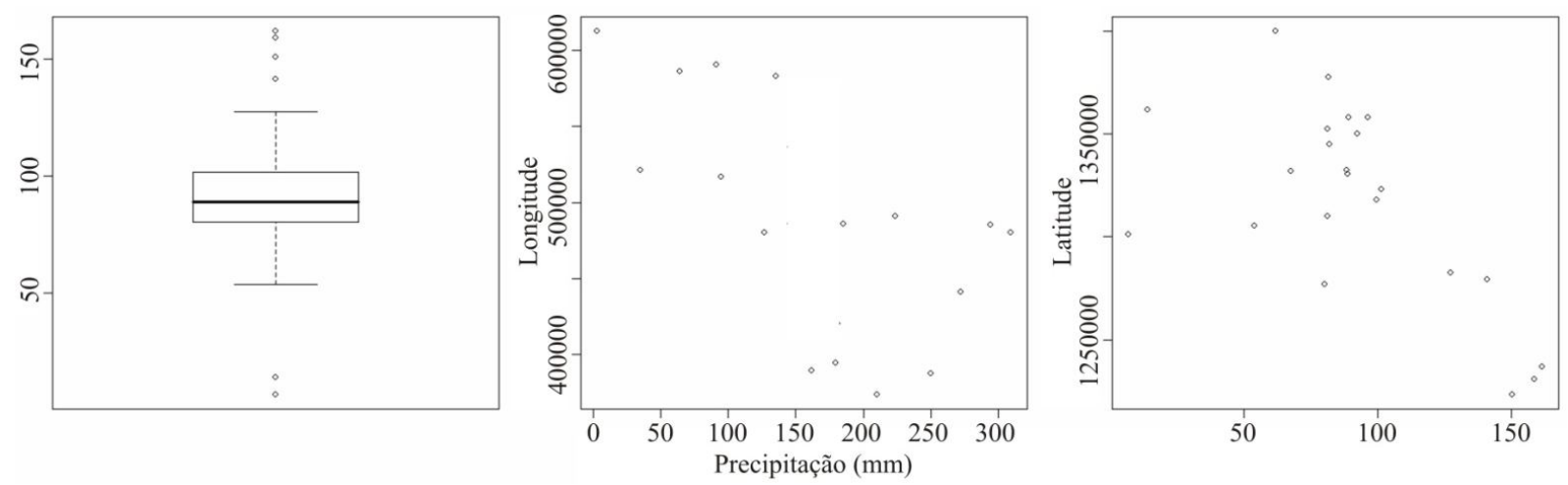

Figura 2. Análise exploratória dos val ores prováveis de precipitação (75\% de probabilidade), para a 2ª quinzena do mês de julho, em Guiné-Bissau 
resultados, tal situação ocorreu para precipitação provável nos meses de junho ( $1^{\mathrm{a}}$ quinzena), julho, agosto e setembro $\left(2^{\mathrm{a}}\right.$ quinzena); salienta-se que os "outliers" foram removidos para prosseguir ao ajuste do semivariograma. Em termos de tendência, não se observou sua presença quando se analisaram os dados nas direções E-W (Longitude) e N-S (Latitude).

Nas Figuras 3 e 4 se encontram os modelos de semivariograma exponencial ajustados pelo método dos
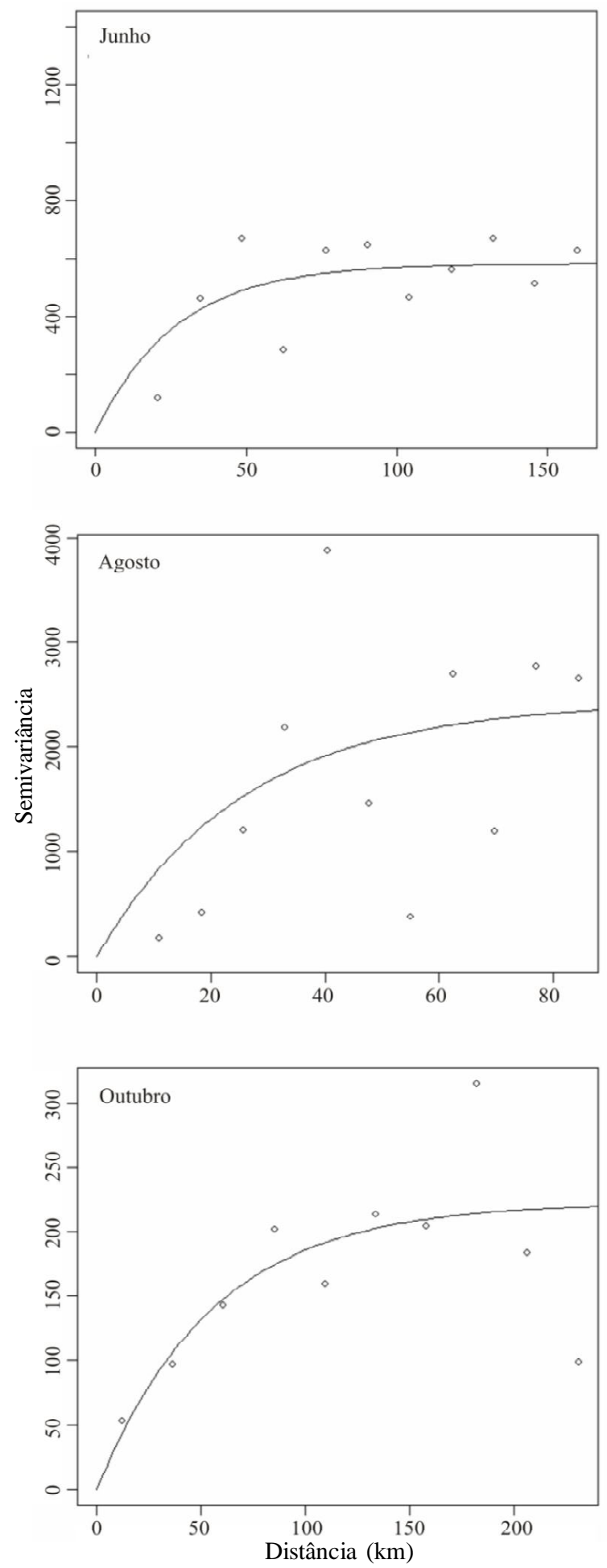

mínimos quadrados ponderados para estimar os valores prováveis de precipitação ( $75 \%$ de probabilidade) para a $1^{\text {a }}$ quinzena e $2^{\mathrm{a}}$ quinzena dos meses de junho a outubro, , cujos parâmetros estão apresentados na Tabela 1 .

$\mathrm{O}$ efeito pepita foi nulo em quase todas as situações, exceto na $2^{\text {a }}$ quinzena do mês de julho, evidenciando que o intervalo de amostragem foi suficientemente adequado para detectar a estrutura de continuidade espacial do fenômeno em estudo.
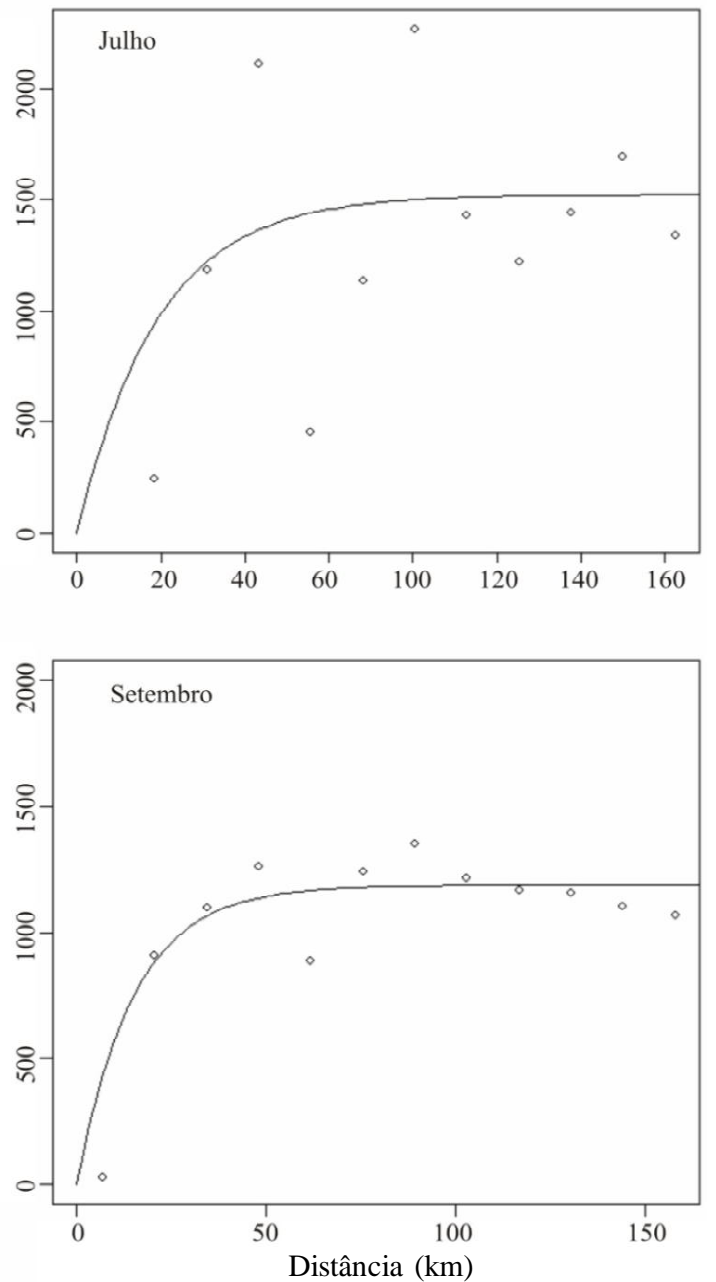

Figura 3. Semivariogramas ajustados aos dados de valores prováveis ( $75 \%$ de probabilidade) para a 1a quinzena, em Guiné-Bissau 

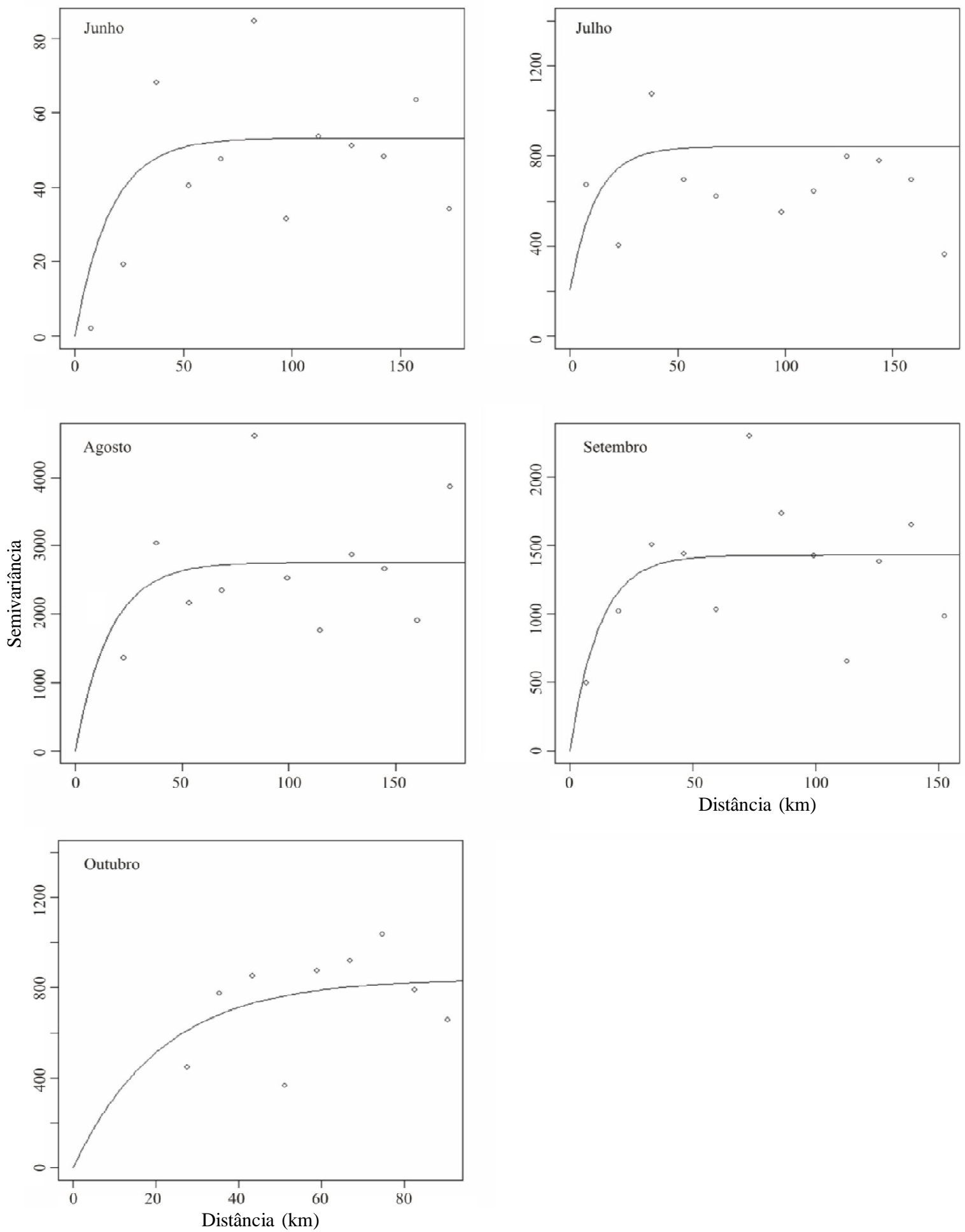

Figura 4. Semivariogramas ajustados aos dados de valores prováveis ( $75 \%$ de probabilidade) para a $2{ }^{a}$ quinzena, em Guiné-Bissau

Observa-se que os modelos de semivariograma exponencial ajustados apresentaram grau de dependência espacial superior a 75\% caracterizando-se, portanto, como de forte estrutura de dependência espacial, conforme relatado por Cambardella et al. (1994). Esta situação permite inferir que a aplicação da krigagem (interpolador geoestatistico) produzirá resultados de boa qualidade com mapas representativos e sem tendência para a precipitação provável (75\% de probabilidade), tanto para $1^{\mathrm{a}}$, como para $2^{\mathrm{a}}$ quinzena dos meses analisados em GuinéBissau (Figuras 4 e 5).

O alcance prático médio para o modelo exponencial foi de $56,2 \mathrm{~km}$ com amplitude de 36,8 a $63,6 \mathrm{~km}$, permitindo identificar a região de influência para cada estação pluviométrica, para os valores prováveis de precipitação para a $1^{\mathrm{a}}$ quinzena; com respeito aos valores prováveis de precipitação para a $2^{a}$ quinzena, o alcance prático médio 
Tabela 1. Parâmetros dos modelos de semivariograma ( $C_{0}$ : efeito pepita; $\mathrm{C}_{0}+\mathrm{C}_{1}$ : patamar; $\mathrm{A}$ : alcance), GD: grau de dependência espacial. 1a e 2a** quinzena para GuinéBissau

\begin{tabular}{lcrcc}
\hline \multirow{2}{*}{ Períodos } & \multicolumn{4}{c}{ Parâmetros } \\
\cline { 2 - 5 } & $\mathbf{C}_{0}$ & $\mathbf{C}_{\mathbf{0}}+\mathbf{C}_{1}$ & Alcance (m) & GD (\%) \\
J unho (1-15) & 0 & 52,20 & 16354 & 100 \\
Junho (16-30) & 0 & 583,18 & 26643 & 75 \\
Julho (1-15) & 204,07 & 639,06 & 11860 & 100 \\
Julho (16-31) & 0 & 1523,36 & 19147 & 100 \\
Agosto (1-15) & 0 & 2761,64 & 16198 & 100 \\
Agosto (16-31) & 0 & 2428,48 & 25835 & 100 \\
Setembro (1-15) & 0 & 1427,45 & 11658 & 100 \\
Setembro (16-30) & 0 & 1186,97 & 15074 & 100 \\
Outubro (1-15) & 0 & 840,48 & 21214 & 100 \\
Outubro (16-31) & 0 & 223,03 & 55721 & 100 \\
\hline
\end{tabular}
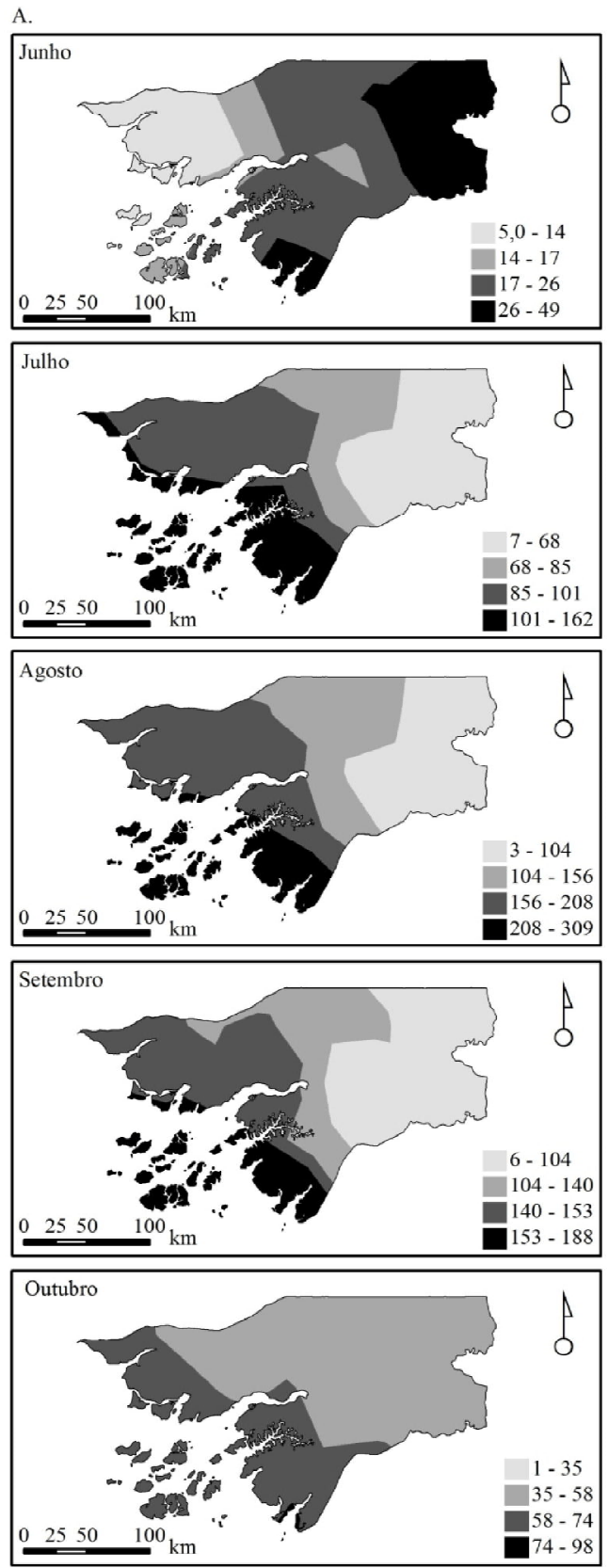

para o modelo exponencial foi de $85,44 \mathrm{~km}$, com amplitude variando de 45,03 a 167,1 km.

Este comportamento está associado, possivelmente, às características de chuvas convectivas predominantes na região, proporcionadas pela zona de convergência intertropical e principais centros de ação regionais semipermanentes, como os anticiclones de Açores e Santa Helena, situados no oceano Atlântico, respectivamente ao norte e ao sul do Equador, determinantes no regime de precipitação no País, proporcionando, desta forma, a existência de dependência espacial num raio de ação menor (Sambu \& Cavalcanti, 2003).

A Figura 5 apresenta os mapas gerados pelo processo de krigagem que descrevem a variabilidade espacial dos valores de precipitação provável $\left(75 \%\right.$ de probabilidade) para as $1^{\mathrm{a}} \mathrm{e} 2^{\mathrm{a}}$ quinzenas dos meses de junho a outubro, em Guiné-Bissau.
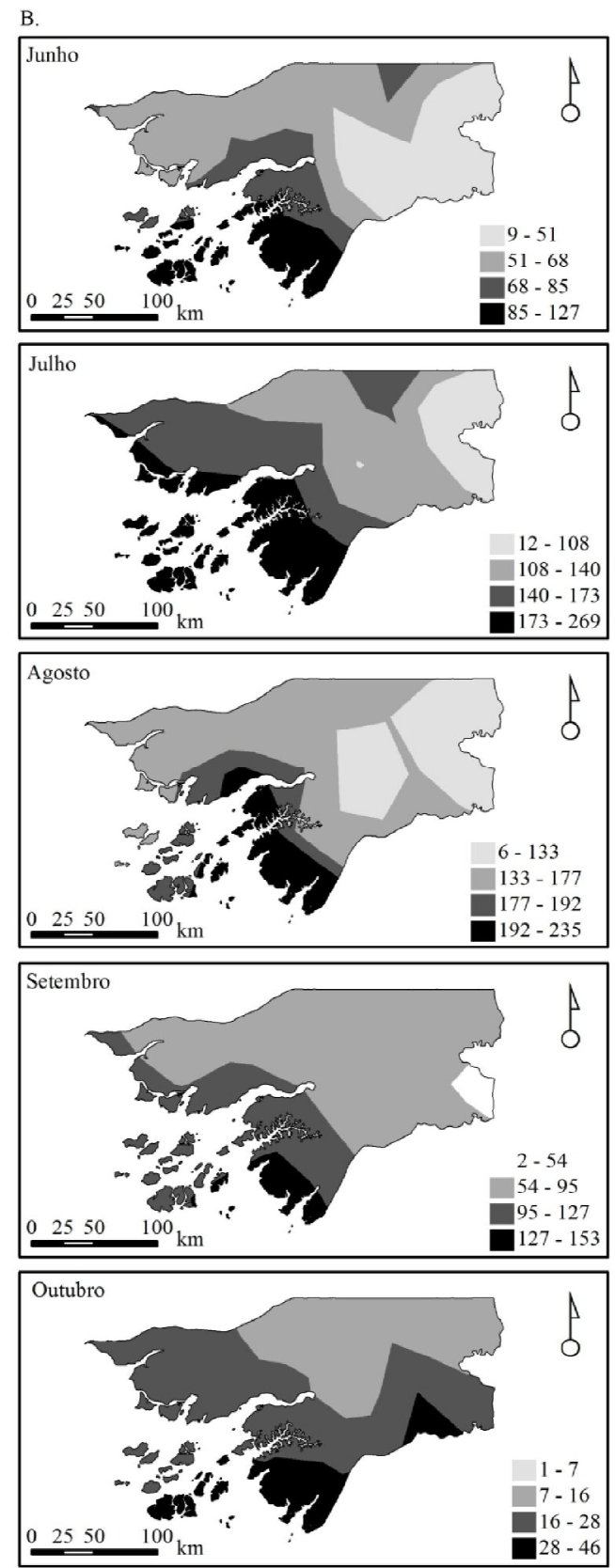

Figura 5. M apas de valores prováveis de precipitação (75\% de probabilidade) para a 1aㅡ (A) e 2aㅡ (B) quinzena em GuinéBissau 
Analisando-se a referida figura, nota-se que os meses de julho, agosto e setembro foram os meses que apresentaram maiores valores de precipitação provável, tanto para a $1^{\mathrm{a}}$, quanto para a $2^{\mathrm{a}}$ quinzena. Sambu \& Cavalcanti (2003) relataram que Guine-Bissau possui duas estações anuais bem definidas, ou seja, o período seco (período entre dezembro a maio) e o período chuvoso (período entre junho a novembro). Os autores observaram que no período chuvoso, especialmente o período compreendido entre os meses de julho a setembro, foi o período que apresentou maior índice pluviômetro, confirmando assim os resultados de valores de precipitação provável encontrados para a região.

Verificou-se que a $1^{\mathrm{a}}$ quinzena do mês do junho foi a que apresentou os menores valores de chuvas prováveis, variando de 5 a $49 \mathrm{~mm}$, sendo a região nordeste aquela que apresenta maiores concentrações. Em termos de manejo agrícola, observase valores de precipitação provável relativamente baixos, sugerindo a utilização de irrigação complementar para o manejo de culturas.

$\mathrm{Na} 1^{\mathrm{a}}$ quinzena mês de julho ocorrem mais de $50 \mathrm{~mm}$ dos valores de precipitação, com $75 \%$ de probabilidade, em toda a faixa que compreende as regiões norte, sudeste e sudoeste do País, verifica-se, ainda, que nos eixos sul-sudoeste para leste e nordeste, os valores das chuvas prováveis seguiram um padrão de redução de lâminas de 162 para $68 \mathrm{~mm}$, respectivamente. Esta tendência pode levar a ocorrências de veranicos para esses locais com índices menores, considerando-se que a magnitude desses valores não se deve apenas ao número de dias chuvosos como, também, a eventos extremos de chuvas características da região.

O mês de agosto, que corresponde ao mês com maiores índices pluviométricos do País, apresenta alta variabilidade nos valores de precipitação provável. Nas regiões sul sudeste e sudoeste, se verificam valores da ordem de 156 a $309 \mathrm{~mm}$ e a região com menores índices abrange os eixos leste e noroeste, com tendência de diminuição de volumes de 156 a $3 \mathrm{~mm}$.

O mês de setembro seguiu o mesmo padrão de distribuição espacial de chuvas prováveis do mês de agosto, com índices relativamente menores podendo-se destacar a região sulsudoeste, com lâminas em torno de $153 \mathrm{~mm}$, e a região noroeste, principalmente seu extremo norte (Pirada) com $104 \mathrm{~mm}$.

Outubro foi o mês que apresentou menores índices dos valores de precipitação provável para a $1^{\text {a }}$ quinzena, superando apenas o mês de junho nesse período, com distribuição espacial heterogênea em todo o País, com variações de 35 a $98 \mathrm{~mm}$, ficando evidente a tendência do padrão espacial da distribuição de precipitação provável com lâminas diminuindo do litoral para o interior do continente. Pode-se verificar, ainda, que as regiões nordeste e sudeste, tal como a maior das regiões leste e nordeste, apresentaram os mesmos índices pluviométricos.

Prosseguindo observou-se, nas análises para a $2^{\mathrm{a}}$ quinzena, a ocorrência de menores concentrações no período, em todo o País, com exceção do mês de julho, que apresentou maiores índices de precipitação provável para a região sul, com índices na ordem de $269 \mathrm{~mm}$. A região norte apresenta, na $2^{\mathrm{a}}$ quinzena de junho, homogeneidade relativa na distribuição de precipitação, com lâminas variando de 68 a $85 \mathrm{~mm}$ e a região sul-sudoeste apresentou maiores índices que diminuem na medida em que avança para o interior do continente; também se constatou, para este mês, que a região noroeste apresenta menores lâminas, variando de 9 a $51 \mathrm{~mm}$.

A $2^{\text {a }}$ quinzena do mês de julho apresentou maiores valores de precipitação provável que a $1^{\text {a }}$ quinzena do mês e se constatou, ainda, que os índices se distribuem de forma heterogênea e os raios que abrangem a região noroeste são os que apresentam menores índices com $108 \mathrm{~mm}$.

Para o mês de agosto ocorreu comportamento semelhante de chuvas prováveis, tanto na $1^{\mathrm{a}}$ como na $2^{\mathrm{a}}$ quinzena; percebese apenas que as lâminas precipitadas são maiores na região norte-nordeste, na $2^{\mathrm{a}}$ quinzena, enquanto na região sulsudoeste apresentam menores índices de precipitação provável em relação à $1^{\text {a }}$ quinzena. O mês de setembro seguiu a mesma tendência da $1^{\mathrm{a}}$ quinzena de agosto mas com uma diminuição acentuada dos índices pluviométricos, em torno de 100 a 153 $\mathrm{mm}$, para a região sul-sudoeste e de 54 a $95 \mathrm{~mm}$ para faixas que compreendem as regiões nordeste, leste, noroeste e sudeste.

A $2^{a}$ quinzena do mês de outubro apresenta comportamento semelhante ao da $1^{\mathrm{a}}$ quinzena do mês de junho, em todo o País, com lâminas variando de 7 a $46 \mathrm{~mm}$, caracterizando o fim do período chuvoso.

Pode-se destacar a predominância, em todo o País, das maiores precipitações na $1^{\mathrm{a}}$ quinzena na maioria dos meses, excetuando-se a $1^{\mathrm{a}}$ quinzena do mês de junho e a $2^{\mathrm{a}}$ quinzena de outubro, que apresentam índices relativamente menores, e a $2^{\mathrm{a}}$ quinzena de julho, que supera as demais, uma evidência do regime transitório sinalizada pela deficiência hídrica interna.

Pode-se destacar a predominância nos índices de precipitação provável em torno de $100 \mathrm{~mm}$ em toda a faixa do território nacional, com exceção da região sul-sudoeste, que apresenta chuvas prováveis acima de $150 \mathrm{~mm}$, caracterizando a variabilidade natural das suas chuvas.

De modo geral, o plantio na $1^{\mathrm{a}}$ quinzena de junho se faz com maior risco. Para regiões situadas a leste e a nordeste, há necessidade de irrigação suplementar considerando-se que a evapotranspiração diária em Guiné-Bissau é de cerca de 4,4 mm (Costa \& Resende, 2004).

Este estudo demonstra que a implantação de sistemas de irrigação na região pode ser necessária na forma suplementar, para suprir a demanda hídrica das culturas.

\section{CONCLusões}

1. Os valores prováveis de totais precipitados em períodos quinzenais apresentam alta variabilidade espacial com evidente decréscimo do eixo sul-sudoeste para norte-nordeste, exceto no mês de setembro, cujo comportamento é homogêneo, tanto para $1^{\mathrm{a}}$ quanto para a $2^{\mathrm{a}}$ quinzena.

2. Em média, pode-se esperar em 3 de cada 4 anos, pelo menos $100 \mathrm{~mm}$ de chuvas para períodos quinzenais, dentro do período chuvoso, excetuando-se a $1^{\mathrm{a}}$ quinzena de junho e a $2^{\mathrm{a}}$ quinzena de outubro que representam, respectivamente, o início e o final do período de chuvas.

3. Para estas duas quinzenas, com a mesma probabilidade de ocorrência, os valores prováveis de chuvas estão abaixo de $50 \mathrm{~mm}$, sinalizando, portanto, a necessidade planejar 
criteriosamente as atividades agrícolas, em particular, os períodos de semeadura (junho) e colheita (outubro, novembro).

\section{LITERATURA CITADA}

Avila, L. F.; Mello, C. R. de; Silva, A. M. Mapeamento da precipitação mínima provável para o sul de Minas Gerais. Revista Brasileira de Engenharia Agrícola e Ambiental, v.13, p.906-915, 2009.

Back, A. J. Application of statistical analysis for identification of climatic tendency. Revista de Pesquisa Agropecuária Brasileira, v.36, p.717-726, 2001.

Baú, A. L.; Gomes, B. M.; Queiroz, M. M. F. de; Opazo, M. A. U.; Sampaio, S. C. Comportamento espacial da precipitação pluvial mensal provável da mesoregião oeste do Estado do Paraná. Irriga, v.11, p.150-168, 2006.

Bernardo, S.; Soares, A. A.; Mantovani, E. C. Manual de irrigação. 8.ed. Viçosa: Imprensa Universitária. 2006. 625p.

Buytaert, W.; Celleri, R.; Willems, P.; Bièvre, B. de; Wyseure, G. Spatial and temporal rainfall variability in mountainous areas: a case study from the South Ecuadorian Andes. Journal of Hydrology, v.329, p.413-421, 2006.

Cambardella, C. A.; Moorman, T. B.; Parkin, T. B.; Karlen, D. L.; Novak, J. M.; Turco, R. F.; Konopka, A.E. Field scale variability of soil properties in Central Iowa soils. Soil Science Society of America Journal, v.58, n.5, p.1501-1511, 1994.

Cano, W. Brandão, C. A. (Coord.). A Região Metropolitana de Campinas: urbanização, finanças e meio ambiente. Campinas: UNICAMP, 2002. 439p.

Carvalho, J. R. P. de; Silveira, P. M. da; Vieira, S. R. Geoestatística na determinação da variabilidade espacial de características químicas do solo sob diferentes preparos. Pesquisa Agropecuária Brasileira, v.37, p.1151-1159, 2002.

Catalunha, M. J.; Sediyama, G. C.; Leal, B. G.; Soares, C. P. B.; Ribeiro, A. Aplicação de cinco funções densidade de probabilidade a séries de precipitação pluvial do estado de Minas Gerais. Revista Brasileira de Agrometeorologia, v. 10, p.153-162, 2002.

Chow, V. T. A general for hydrologic frequency analysis. Transactions of American Geophysical Union, v.32, p.231237, 1951.

Costa, C.; Resende, M. Guiné Bissau: O ambiente agrícola homem e uso da terra. Viçosa: Agropecuária. 1994. 290p.

Doorenbos, J.; Kassam, A. H. Efeito da água no rendimento das culturas. Campina Grande: UFPB, 1994. 306p. Estudos FAO Irrigação e Drenagem 33.

ESRI - Environmental Systems Research Institute. ArcGIS 9.2: Getting started with ArcGIS. Redlands: 2004. 265p.

Journel, A. G.; Huijbregts, C. J. Mining geostatistics. London: Academic Press, 1978. 600p.

Junqueira Júnior, J. A.; Gomes, N. M.; Mello, C. R. de; Silva, A. M. da. Precipitação provável para a região de Madre de Deus, Alto Rio Grande: modelos de probabilidades e valores característicos. Ciência e Agrotecnologia, v.31, p.842- 850, 2007.

Longo, A. J.; Sampaio, S. C.; Queiroz, M. M. F.; Sussek, M. Uso das distribuições gama e log-normal na estimativa de precipitação provável quinzenal. Varia Scientia, v.6, p.107118, 2006.
Manafá, B; Semedo, S.; Vieira, R.; Silva, V. B.; Costa, M. C. Guiné Bissau em números, Bissau, 1.ed. República GuinéBissau: Nova Gráfica Ltda. 2005. 43p.

Marquinez, J.; Lastra, J.; Garcia, P. Estimation models for precipitation in mountainous regions: the use of GIS and multivariate analysis. Journal of Hydrology, v.270, p.1-11, 2003.

Mello, C. R. de; Lima, J. M.; Silva, A. M.; Mello, J. M.; Silva, M. S. Krigagem e inverso do quadrado da distância para interpolação dos parâmetros da equação de chuvas intensas. Revista Brasileira de Ciência do Solo, v.27, p.925-933, 2003.

Mello, C. R. de; Silva. A. M. Modelagem estatística da precipitação mensal e anual e no período seco para o estado de Minas Gerais. Revista Brasileira de Engenharia Agrícola eAmbiental, v.13, p.68-64, 2008.

Mello, C. R. de; Viola, M. R.; Mello, J. M.; Silva, A. M. Continuidade espacial de chuvas intensas no estado de Minas Gerais. Ciência eAgrotecnologia, v.32, p. 532-539, 2008.

Mello, J. M. de; Batistia, J. L. F.; Ribeiro Júnior, P. J.; Oliveira, M. S. Ajuste e seleção de modelos espaciais de semivariograma visando à estimativa volumétrica de Eucaliptus grandis. Scientia Florestalis, v.1, p.25-37, 2005.

Oliveira, J. P. B.; Cecílio, R. A.; Xavier; A. C.; Jasper,A. P. S; Oliveira, L. B. Precipitação Provável para Alegre-ES através da distribuição de probabilidade gama. Engenharia Ambiental, v.7, p.204-211, 2010.

R Development Core Team. R: A language and environment for statistical computing. R Foundation for Statistical Computing, Vienna, Austria. URL http://www.R-project.org, 2006. 10 Out. 2009.

Ribeiro, B. T.; Avanzi, J. C; Mello, C. R. de; Lima, J. M. de; Silva, M. L. N. Comparação de distribuições de probabilidade e estimativa da precipitação provável para a região de Barbacena, MG. Ciência e Agrotecnologia, v.31, p.1297-1302, 2007.

Ribeiro Júnior, P. J. Métodos geoestatísticos no estudo da variabilidade espacial de parâmetros do solo. Piracicaba: ESALQ/USP, 1995. 99p. Dissertação Mestrado

Sambu, F. B.; Cavalcanti, I. F. A. Variabilidade climática da precipitação na região de Guiné-Bissau - A situação sinóptica e a influência dos sistemas convectivos. In: Congresso de Pós-Graduação em Ciências da Terra, Clima e Espaço da Universidade de Évora, 2003, Évora. Resumos... Évora: Universidade de Évora, 2003. p 67-68.

Soccol, O. J.; Cardoso, C. O.; Miquelluti, D. J. Análise da precipitação mensal provável para o município de Lages, SC. Revista Brasileira de Engenharia Agrícola e Ambiental, v.14, p.569-574, 2010.

Vieira, S. R. Geoestatística em estudos de variabilidade espacial do solo. In: Novaes, R.S.; Alvarez, V. V. H.; Schaeser, C. E. G. R. Tópicos em Ciências do Solo. Viçosa: Sociedade Brasileira de Ciência do Solo, 2003. v.3, p.1-54.

Viola, M. R.; Mello, C. R. de; Pinto, D. B. F.; Mello, J. M. de; Avila, L. F. Métodos de interpolação espacial para o mapeamento da precipitação pluvial. Revista Brasileira de Engenharia Agrícola e Ambiental, v.14, p.970-978, 2010. 